\title{
VTOL Urban Air Mobility Concept Vehicles for Technology Development
}

\author{
Christopher Silva* and Wayne Johnson ${ }^{\dagger}$ \\ NASA Ames Research Center. Moffett Field, CA 94035 \\ Kevin R. Antcliff* and Michael D. Patterson ${ }^{\S}$ \\ NASA Langley Research Center, Hampton, VA 23681
}

\begin{abstract}
The current push for Urban Air Mobility (UAM) is predicated on the feasibility of novel aircraft types, which will be enabled by the near-term availability of mature technology for high performance subsystems. A number of candidate concept aircraft are presently being designed to meet a set of UAM requirements, in order to quantify the tradeoffs and performance targets necessary for practical implementation of the UAM vision. In examining these vehicles, performance targets and recurring technology themes emerge, which may guide investments in research and development within NASA, other government agencies, academia, and industry.
\end{abstract}

\section{Nomenclature}

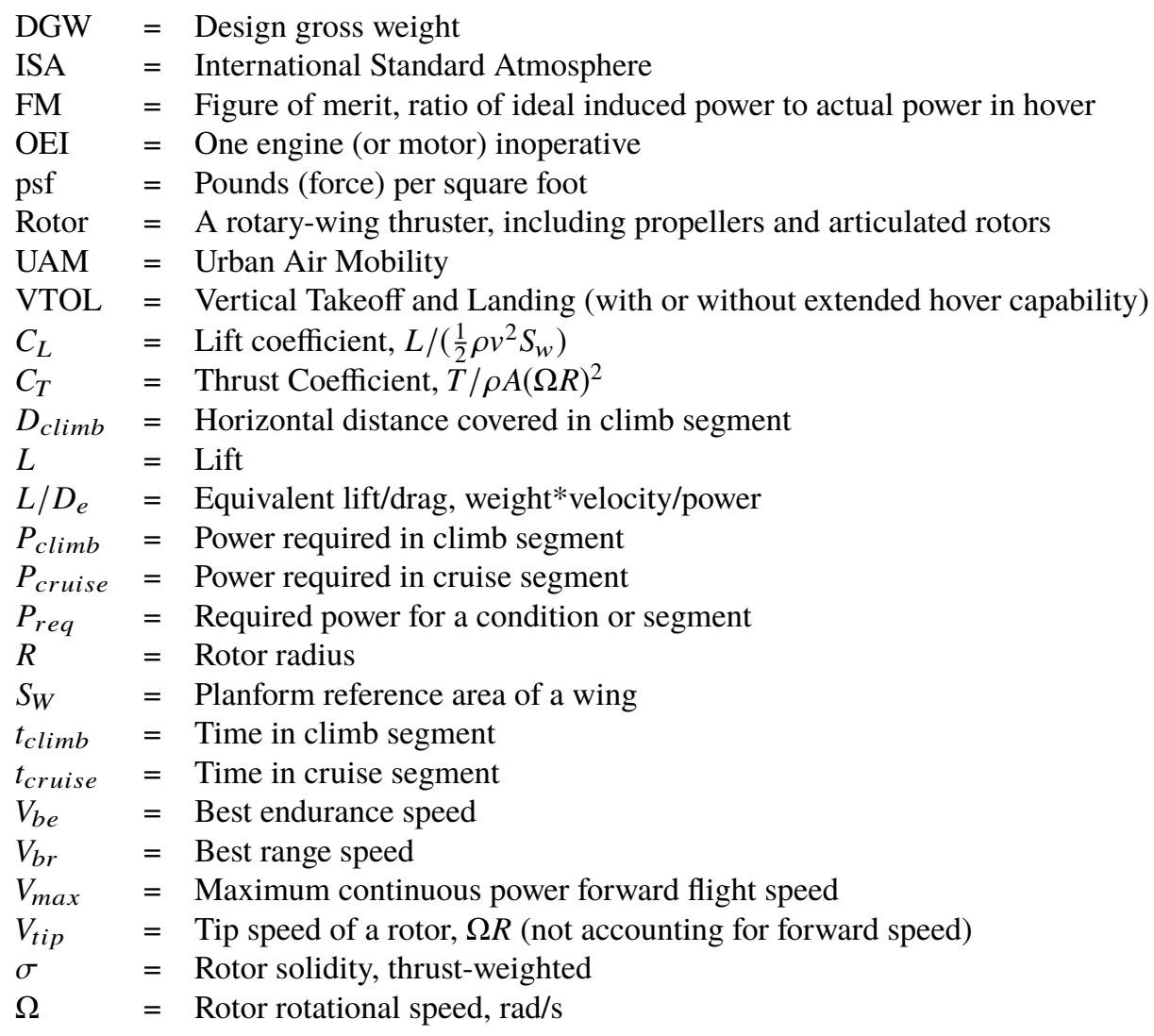

\footnotetext{
* Research Aerospace Engineer, Member AIAA

NASA Ames Fellow, AIAA Fellow

$¥$ Aerospace Engineer, Aeronautics Systems Analysis Branch, MS 442, Member AIAA.

$\S$ Aerospace Engineer, Aeronautics Systems Analysis Branch, MS 442, Member AIAA.
} 


\section{Introduction}

$\mathrm{T}$ ECHNOLOGY development typically proceeds either of its own accord, or in response to an externally defined need. In the present study, we are using specific aircraft conceptual designs in order to establish the feasibility of meeting a set of challenging vehicle requirements, and to quantify the levels of performance needed from component technologies in order to realize aircraft meeting those requirements. The conceptual designs and their requirements may serve as need statements that researchers can use to understand the impact of their work on the market for Urban Air Mobility (UAM). The concept vehicles described in the present paper are provided as reference vehicles, such that research and development may be prioritized by its quantifiable system-level payoff. The present paper is part of a series of publications, including [1] and [2], which explore UAM aircraft requirements and technology trades. The present study is focused on a $1200 \mathrm{lb}$ payload weight—up to six passengers — design mission, and describes the vehicles that result from these requirements. The current aircraft supplement the previous concept aircraft [1], and examine the implications of performing a relevant UAM mission [2]; a small quadrotor aircraft has been scaled up to meet these specific requirements, and a new type of aircraft, a "lift+cruise," has been added to the types of aircraft considered, because it has features which explore some particular technology trades relevant to aircraft being proposed by industry.

NASA technology development includes not only physical hardware and flight vehicle software, but also the tools for performing design and analysis of aircraft system-of-systems. The concept vehicles and the design process itself have tested the ability of our tools and will lead to improvements going forward.

\section{Tools}

Several tools exist to model and design advanced vertical takeoff and landing (VTOL) aircraft; the current tool suite and design process has been described in greater detail in Ref. [3]. The primary sizing and analysis tool used in the present study is NASA Design and Analysis of Rotorcraft (NDARC) [4], which has broad applicability to conventional and unconventional types of aircraft, with models for multiple rotors and lifting surfaces, various engines and motors, and for several forms of energy storage and conversion. One of the key capabilities of NDARC is its ability to perform requirements and technology trades quickly and consistently, which makes NDARC well suited to the task of evaluating component technology contributions. For this study, NDARC version 1.13 has been developed and employed, with new features to allow modeling of stopped-rotors.

We applied geometry tools OpenVSP [5] and the commercial software Rhinoceros 3D, which allow rapid generation of conceptual models and high-quality geometry for visualization and CFD simulations. Rotor design and surrogate model generation employs CAMRAD II [6], which can evaluate free wake interactions within and among rotors and wings. Design space exploration was facilitated by using OpenMDAO 1.7 [7] and the rcotools library [8].

\section{Requirements}

The design requirements are encapsulated in the sizing mission, sizing conditions, required equipage, layout considerations, and technology assumptions. In the present study, we built upon the significant existing literature on "On Demand Mobility" and "Urban Air Mobility" concepts of operation, and have applied our own synthesized definition of UAM mission and condition requirements that we use in sizing and evaluating aircraft, as defined in Ref. [2]. These requirements were refined by considering the results of several NASA-sponsored and NASA-executed activities, as well as the models presented by others. These requirements account for the existing geography, population patterns, infrastructure, and weather in twenty-eight markets across the United States of America.

A description of the primary design mission segments is presented in Table 1 and these segments are represented in a mission profile in Fig. 1. In the sizing mission, we require the aircraft to complete two separate flights of $37.5 \mathrm{nmi}$ into a headwind of 10 knots with a reserve of 20 minutes at cruise power. Several mission segment parameters in the table are left unspecified, such as the speeds for different segments. In these cases, we allow the aircraft to operate in a manner that is most efficient for that vehicle. Other mission requirements are described in Ref. [2].

Sizing requirements in addition to those specified in Ref. [2] are required for sizing the battery in the turboelectric Lift+Cruise aircraft. A battery sizing mission representing a failure of the turboshaft engine and a hover out of ground effect for not less than 2 minutes and with battery discharge current less than the maximum burst discharge rate is proposed. 
Table 1 Sizing mission segments and their associated properties

\begin{tabular}{lllllllllll} 
Segment & 1 & 2 & 3 & 4 & 5 & 6 & 7 & 8 & 9 & 10 \\
\hline \hline Initial Alt. (MSL ISA) & 6,000 & 6,000 & 6,050 & 6,050 & 10,000 & 6,050 & 6,050 & 6,050 & 6,000 & 10,000 \\
Final Alt. (MSL ISA) & 6,000 & 6,050 & 6,050 & 10,000 & 10,000 & 6,050 & 6,050 & 6,000 & 6,000 & 10,000 \\
Time (sec) & 15 & 30 & 10 & $t_{\text {climb }}$ & $t_{\text {cruise }}$ & 10 & 30 & 30 & 15 & 1200 \\
Distance (nmi) & - & 0 & 0 & $D_{\text {climb }}$ & $37.5-D_{\text {climb }}$ & 0 & 0 & 0 & 0 & - \\
Speed & - & - & 0 & $V_{y}$ & $V_{b r}$ & 0 & 0 & - & - & $V_{b r}$ \\
ROC (ft/min) & - & 100 & 0 & $\geq 900$ & 0 & 0 & 0 & -100 & - & 0 \\
Percent of Max Power & $10 \%$ & $100 \%$ & $100 \%$ & $P_{\text {climb }}$ & $P_{\text {cruise }}$ & $100 \%$ & $100 \%$ & $100 \%$ & & \\
\hline
\end{tabular}

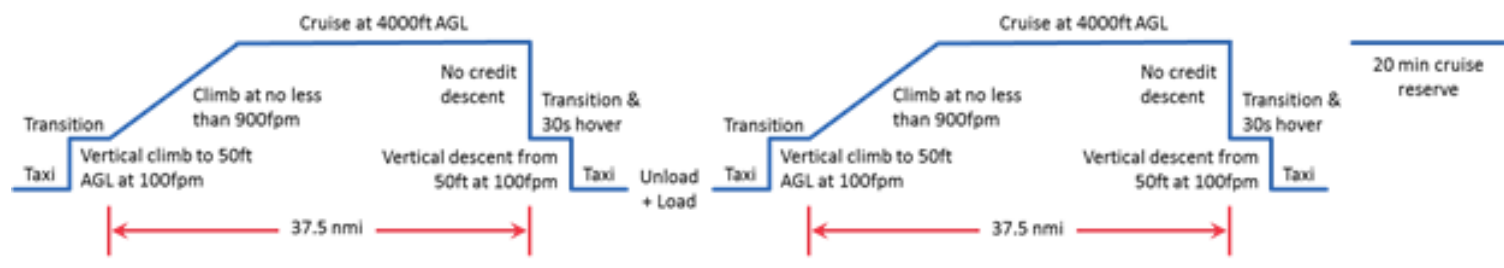

Fig. 1 Sizing mission profile

\section{Conceptual Aircraft Designs}

Multiple aircraft conceptual designs have been developed for this study, spanning several types of aircraft. These concept vehicles are intended to represent the general features of aircraft which may be considered for UAM missions. The vehicle descriptions have enough fidelity to capture the important compromises which must be embodied in an actual aircraft, while avoiding appearing too similar to any particular aircraft being proposed by prominent members of industry. In our usage, a "type" refers to the general layout and control strategy of an aircraft. For instance a single main rotor helicopter, a tiltrotor, a quadrotor, or a fixed-wing propeller aircraft are all distinct types of aircraft. Similarly, in this usage, a specific instantiation of an aircraft type, with particular technologies and otherwise described in some detail, is a "concept" aircraft. Whenever possible, an aircraft type will be referred to by a lowercase name, and a concept vehicle will be capitalized in title case.

The question of which aircraft type is optimally suited to performing economically viable Urban Air Mobility missions has been and will continue to be the subject of much debate. Rather than propose to identify the singular best type of vehicle (which may be determined as "best" for a non-technical and perhaps even non-economic reason), this study is considering a broad variety of types of vehicles which appear to be viable given our current understanding of UAM markets.

The primary purpose of these vehicles is to identify technologies and tools, and establish criteria for how those technologies will buy their way on to the aircraft or how they will enable viable aircraft. For each type of aircraft selected, concepts with varying technology and design approaches were designed and analyzed. These models exist as NDARC input and output files, CAMRAD II inputs and outputs, and OpenVSP and Rhino geometry models.

Prior surveys of the state-of-the-art and known development programs led us to choose aircraft which include both rotor- and wing-borne cruise strategies, and which have various propulsion approaches including mechanical and electrical power distribution. We had previously [1] identified 3 different aircraft types (quadrotor, side-by-side helicopter, and tilt-wing) to serve as reference vehicles across a range of missions, technologies, and design approaches. From those types, reference vehicles were designed to meet a selection of design missions which varied occupants from 1 to 15 and also varied unrefueled capability from 1 round-trip to 8 trips for a transport mission with $50 \mathrm{~nm}$ range. The wide variation in missions was necessary due to the nebulous definition of "urban" and the uncertainty surrounding the ultimate economically viable urban air mobility mission. Research using the earlier reference vehicles has already commenced within NASA, and the conceptual vehicle models themselves have been made available to the NDARC user community, which extends beyond NASA to US DoD, academia, industry, and foreign academia.

More recent work on developing a UAM mission set [2] has led to a synthesized mission profile which represents an empirical sizing mission, suitable for the needs of aircraft which may serve a large number of US metropolitan areas. In the present paper, multiple concept aircraft have been designed to that mission set, with the addition of a new type of 
aircraft, which we refer to as being of the "lift+cruise" type. The lift+cruise type displaces the tilt-wing type in this study, since lift+cruise is also a strong candidate for turboelectric propulsion, and is well-suited to represent distributed electric propulsion. The tilt-wing continues to be considered for our technology development purposes, but little new insight beyond that previously discussed was expected to be gained by sizing it to these requirements. Because the lift+cruise type is a new type of aircraft, we will be discuss this aircraft in much greater detail than the other vehicle types, which are described in Ref. [1].

\section{A. Quadrotor}

The basic features and some technology and requirement trades and sensitivities of the NASA UAM quadrotor aircraft are described in Ref. [1]. However, there are some differences between the concept aircraft in the earlier study and that in the present study. For this study, a significantly larger payload of 6 occupants at $1200 \mathrm{lb}$ total versus the earlier 1 occupant for $220 \mathrm{lb}$ results in a very different concept aircraft, with a large fuselage and very large rotors, depicted in Fig. 2

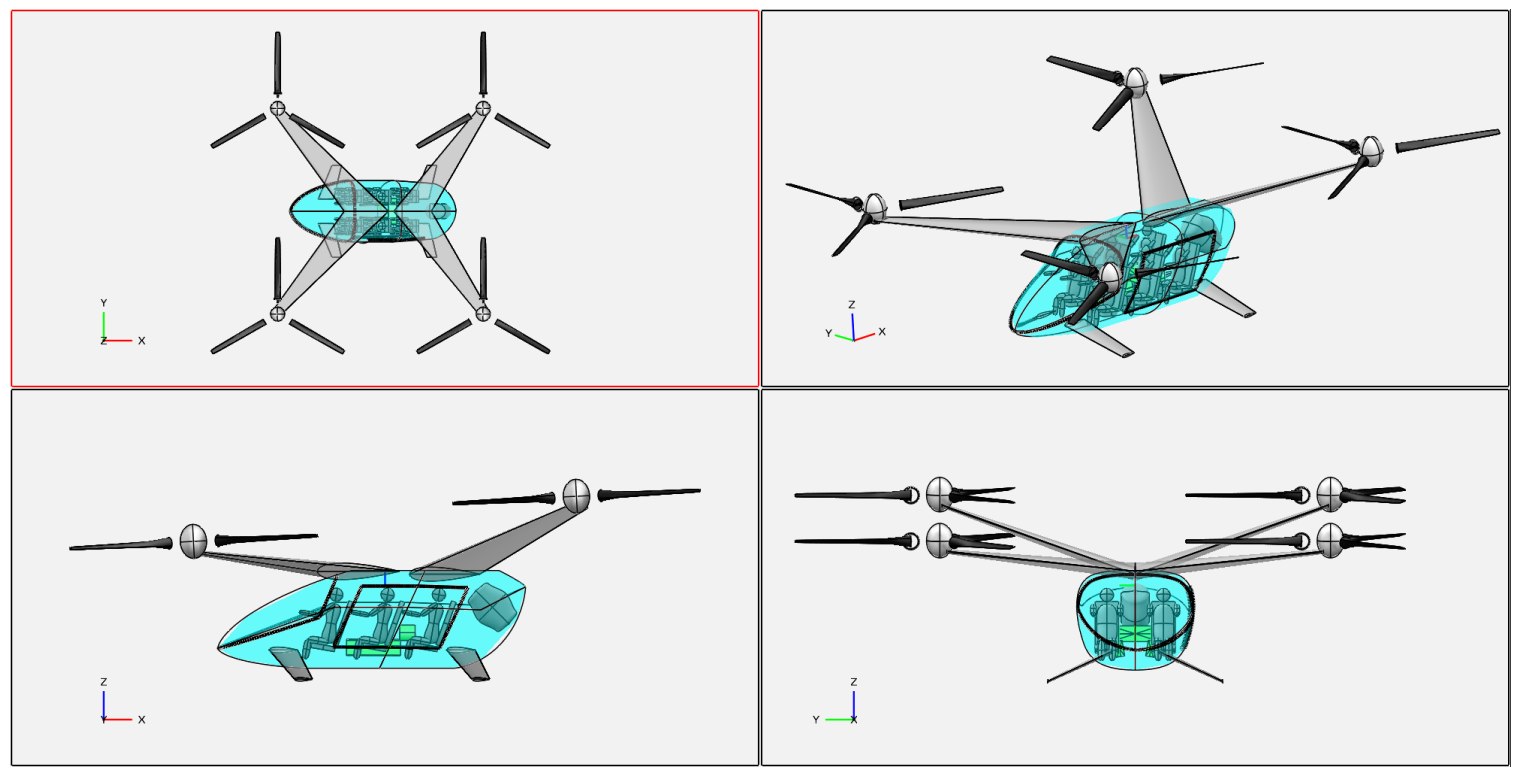

Fig. 2 Turboshaft-powered Quadrotor concept vehicle

Two separate quadrotor concept aircraft have been designed, one turboshaft-powered mechanical drive, and the other a battery-powered electric drive. The much larger rotors of the six-passenger aircraft are unlikely to be conducive to RPM control, and only collective control was considered for these concept vehicles. As in the previous work, the drive system for collective control links all of the engine groups ( 1 engine group for turboshaft, 4 engine groups for electric motors) to a single propulsion group so that the loss of any motor, or even all motors, does not result in any rotor losing the ability to take power from elsewhere in the propulsion group via shaft power transmission. We expect that the ability to share power in this way will reduce the conditions under which the aircraft will run out of maneuver margin while autorotating, due to the need to maintain rotor speed for energy management. Time-marching autorotation simulations are planned for the earlier single-passenger collective- and RPM-controlled vehicles to establish limitations of each.

The two propulsion architectures for the quadrotor concepts are depicted in Fig. 3. with the forward right rotor labeled as yellow circle 1 and forward left rotor as 2 . The propulsion architecture schematics are presented as approximate top-views of the aircraft, with the front of the aircraft at the top of the figure. For these figures, yellow circles with orange outlines are rotors (NDARC Rotor components); orange trapezoids with orange outlines are transmission gearboxes and thick orange connecting lines are drive shafts (NDARC Propulsion components); blue circles with orange borders are motors and generators (NDARC EngineGroup components which point to MotorModel components); blue rectangles with blue borders are batteries and blue connecting lines are wires and interconnects (NDARC FuelTank components which point at BatteryModel components); green circles with orange borders are fuel-burning engines with shaft output (NDARC EngineGroup components which point at EngineModel components); green rectangles with green borders are fuel tanks and green connecting lines are fuel plumbing (NDARC FuelTank components). Thus, the blue lines represent 
electrical transfer of power and the orange lines represent mechanical transfer of power in these figures. Rotor direction of rotation is represented by the orange arc-arrows. The relative size of components (e.g. battery and fuel tank) are not intended to represent any physical scale.

For the Battery-powered Electric Quadrotor, the motors are located at the ends of the booms near the rotors, and connected to a local speed-reducing gear which drives the rotor. A higher-speed (low torque) drive shaft is connected to another input to the local gearbox, and is connected to a central combining gearbox. The motors are shown away from the rotors to clarify the NDARC model topology, which treats the gearboxes and shafts as one "propulsion group."

One aspect which was examined in previous analysis of the quadrotor is that in forward flight, the power required by the rear rotors is often greater than that required by the front rotors, even with a vertical offset between front and rear. By combining the motors into one propulsion group, a higher top speed is achievable with a single motor size. In the case of independent mechanical drives, top speed is limited by the rear motors reaching their power limit while the front motors have more power available. A single motor size is desirable from an acquisition and support cost standpoint, as a larger number of identical motors may be purchased, and fewer distinct motors types must be stocked. A single gearbox may be used (perhaps in right- and left-hand variants), with the weight penalty for extra rated power in front gearboxes lower than would be the case for oversized motors.

For the Turboshaft Quadrotor, the motor is located in the fuselage, and feeds the combiner gearbox at high speed, which then distributes power via high-speed shafts to local reducing gearboxes at the rotors. Not shown are overrunning clutches at the motors and engines; these are not explicitly modeled in NDARC, but historical drive systems have been successfully modeled with NDARC. The overrunning clutches allow operation of the balance of the drive train in case of a single motor or engine failing.

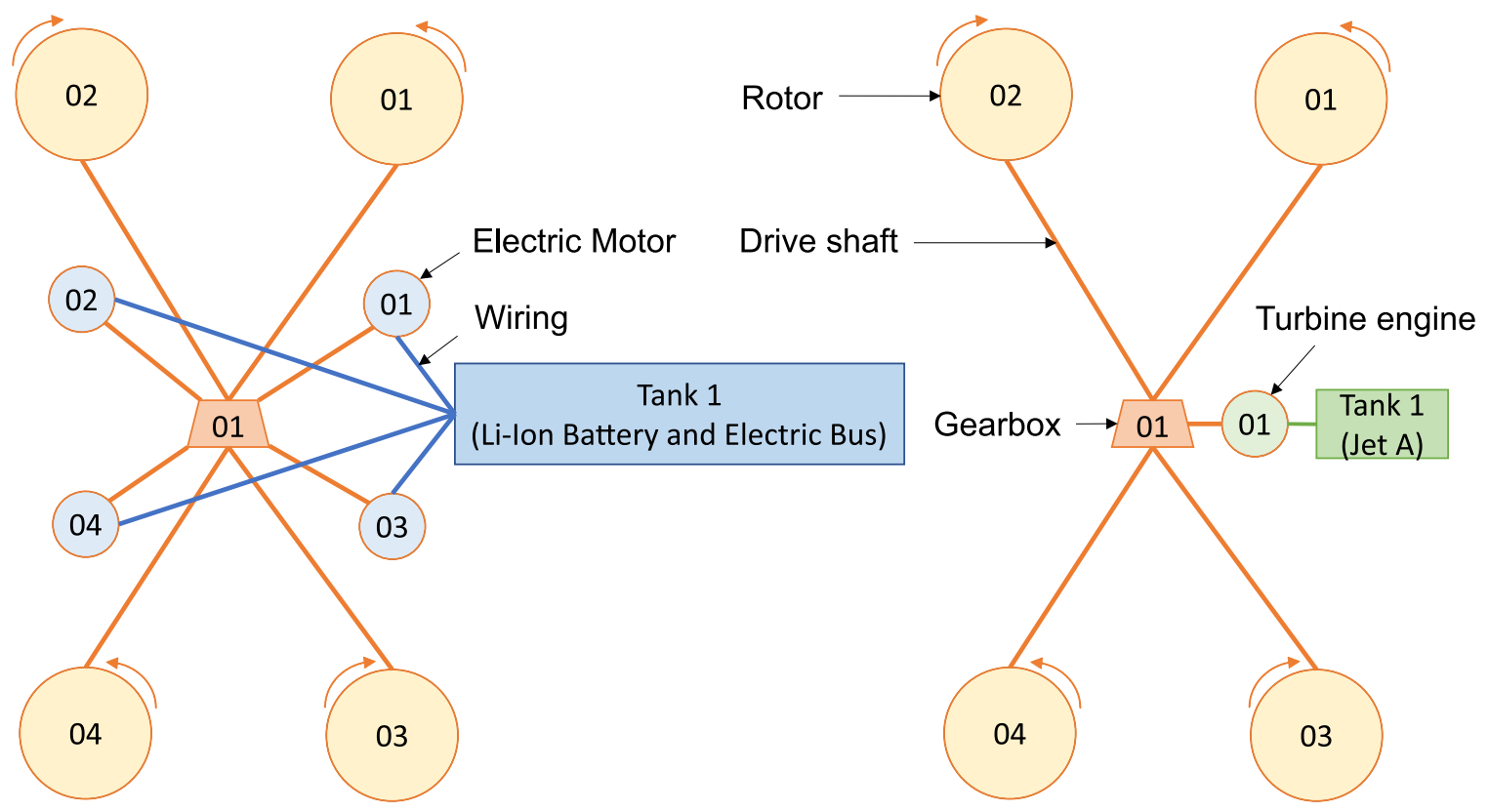

Fig. 3 Representation of Electric (left) and Turboshaft (right) Power Topologies for Quadrotor

\section{B. Side-by-Side Helicopter}

The basic side-by-side helicopter designed for NASA UAM is described in Ref. [1], and a more complete discussion of the performance of the side-by-side rotor system is found in Ref. [3]. The most noteworthy attribute of the aircraft is its overlapping and intermeshing pair of main rotors, which act as a single lifting and thrusting actuator in forward flight, with a much larger effective span than either rotor in isolation. In the present study, the range is reduced from 4 x 50 $\mathrm{nm}(200 \mathrm{~nm})$ to $2 \times 37.5 \mathrm{~nm}(75 \mathrm{~nm})$ relative to the mission used for sizing the earlier side-by-side. The Turboshaft Side-by-Side concept vehicle is depicted in Fig. 4.

Two concept side-by-side aircraft were designed, one with two turboshaft engines, and another powered by batteries with two electric motors. The motors and engines are located near the rotors at the ends of the rotor support cross-bar. 
As in the depiction of the quadrotor drive systems, the motors and engines are shown displaced from the rotors to clarify the modeling connection, whereby a single NDARC propulsion group is connected to both motors/engines and both rotors. The propulsion group represents two drive systems and the interconnect shaft. The drive system topologies are depicted in Fig. 5

The interconnect shaft in the side-by-side serves two primary purposes, synchronization and power transfer. The intermeshing rotors must remain synchronized, and this is typically a low-power, low-torque condition. The case of one engine or one motor inoperative is mitigated by using the shaft to send power from the side with an operative motor/engine to the other side of the vehicle. The shaft is therefore a critical component in the drive system, and sized for torque by one engine inoperative, but sized for life by the synchronization loads over a long period of active operation.

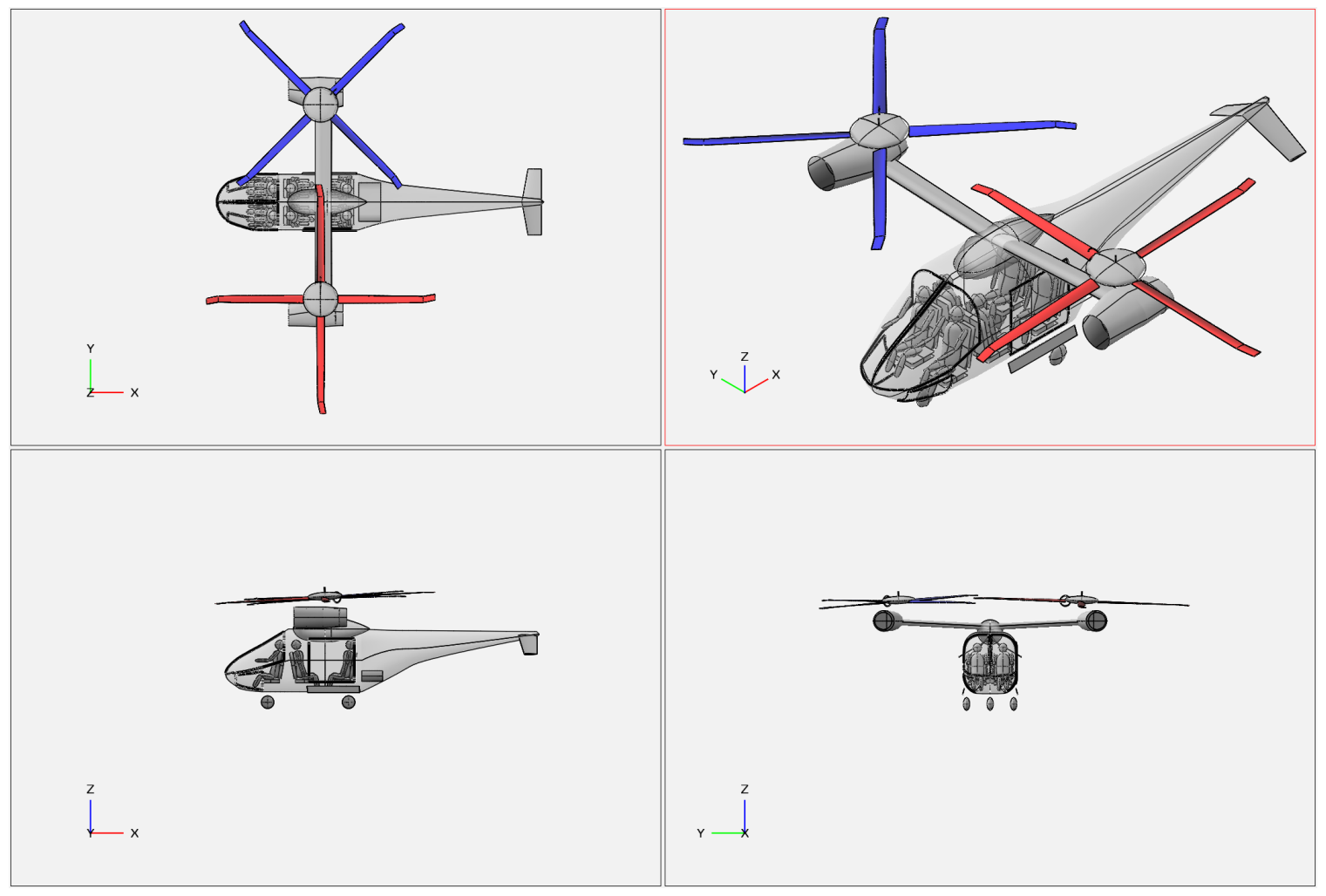

Fig. 4 Turboshaft-powered Side-by-Side concept vehicle

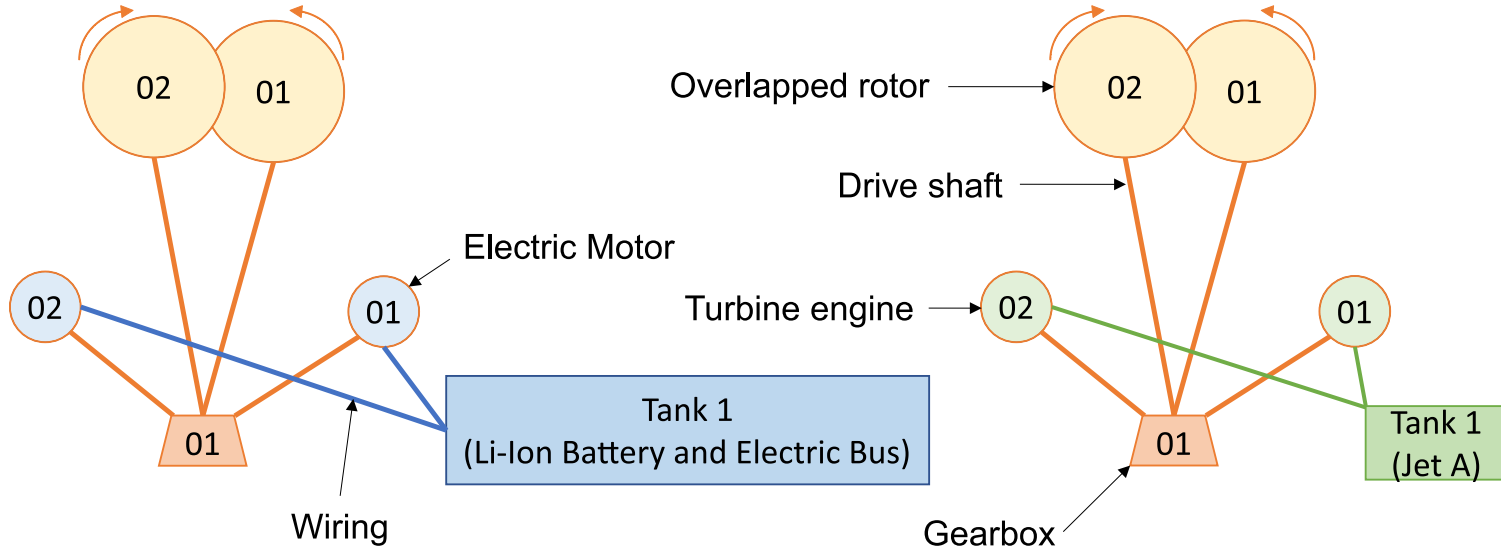

Fig. 5 Representation of Electric (left) and Turboshaft (right) Power Topologies for Side-by-Side 


\section{Lift+Cruise VTOL Aircraft}

The lift+cruise type of aircraft is intended to represent a class of VTOL aircraft which have been developed recently and documented in magazine articles (e.g. Ref. [9] and Ref. [10]) for manned and unmanned operation, taking advantage of distributed electric propulsion. The lift+cruise vehicle is intended to operate as a fixed-wing aircraft whenever possible, and operate the VTOL lift rotors only during the VTOL takeoff and landing phases of flight. The most distinctive attribute of these concepts is that the rotors for lift are separate from those used for propulsion, and the lift rotors are not used (stopped and aligned with flow) during cruising flight. As such, the lift rotors are intended to generate small aerodynamic forces and moments during cruise.

Some of the potential benefits of the lift+cruise type are identified and listed below. This list was used as a guide for designing and analyzing the lift+cruise concept aircraft in this study.

1) Electrical power distribution allows a nearly scale-free production of lift, due to the flat scaling of weight with size of electric motors, as compared to turboshafts and reciprocating engines. Therefore, many small motors should be no heavier than few large motors.

2) Multicopter-style redundancy can be employed to deal with failures in the lifting system. Any number of rotors greater than 6 allows a fairly simple and manageable continuation of controlled 6 degree-of-freedom flight.

3) Simple propellers with RPM control can be used, since the propeller/rotors are small. No collective or cyclic actuation is required, and the blades do not need articulation since they never operate at high edgewise speed.

4) The small rotors and motors in the lifting system can be all of the same design (with perhaps only clockwise and counter-clockwise differences), allowing economy of scale in manufacturing and simplified support logistics.

5) If 2-bladed rotors are used, then a simple indexing mechanism allows them to be stopped while aligned with the direction of travel in airplane mode for only a small drag penalty.

6) A small wing, optimized for cruise, can be used, since slow-speed flight is performed with lift augmentation from the propellers. Cruising in airplane mode can result in significant energy reduction, yielding smaller installed batteries and making electric propulsion more realizable.

7) Only limited hover and low-speed flight are required for many envisioned UAM missions, therefore certification can be through a primarily fixed-wing set of regulations, with the VTOL portions as exceptions or additions.

8) Because the hover energy is small compared to the cruise energy due to the large difference in time spent in each mode offsetting the much greater hover power, a higher disk loading may be tolerated without significantly growing the battery.

9) Because the aircraft flies more like a fixed-wing aircraft while enroute and when departing/arriving a vertiport, the acoustics are more akin to fixed-wing general aviation and will be found to be less objectionable by the public.

10) The large number of rotors and electric motor propulsion will allow the lift rotors to operate at low tip speeds, which will greatly diminish noise relative to an aircraft with fewer large rotors.

The current Turboelectric Lift+Cruise concept aircraft is depicted in Fig. 6, and has 8 lifting rotors and a single pusher propeller. The selection of 8 rotors for the vehicle was somewhat arbitrary, and excursions to greater numbers of rotors will be performed in the near future. We are aware of lift+cruise aircraft which have as few as 4 and as many as 12 distinct lifting rotors. Our selection of rotor placement is also a design choice; rotor placement on booms also can vary, with the potential for as few as one rotor per boom or as many as half of the rotors all mounted on a boom. For the lift+cruise concept vehicles, rotor numbering follows a convention familiar to multi-engine fixed wing: left-to-right, front-to-back. The first 8 rotors are the lifting rotors in this numbering convention, and the numbering scheme should be natural for a pilot or operator to follow and quickly find on a graphical display. Fig. 7 is a rough spatial top-view representation of the Turboelectric Lift+Cruise aircraft rotor layout with the upper part of the figure being the forward end. As in previous propulsion architecture figures, conceptual linkages of power flow through components and numbering match those in the NDARC model. For RPM-control of rotors, there are no mechanical links between drive systems, and the motors are connected to a single gearbox and rotor. The numbering has been selected such that a battery-powered variant can omit the final two EngineGroup components and the final Propulsion component without requiring changes to the rest of the control settings and component linkage numbering.

The power flow throughout the system is tightly coupled with the control in hover and conversion for the lift+cruise aircraft. The NDARC model reflects this, as the Propulsion component adjusts rotor speed, not the Rotor component. For the battery-electric aircraft, a single battery is modeled connected to all of the motors for the purposes of sizing the aircraft. Various failure modes must be considered, and topologies with multiple batteries serving all or some of the motors are also feasible; these trades will be performed in the coming months.

In the turboelectric version, a new turboelectric propulsion group is used to feed power into and through the battery/bus of the battery-only model. Modeling the turboelectric bus as a battery in NDARC is required, because that is 


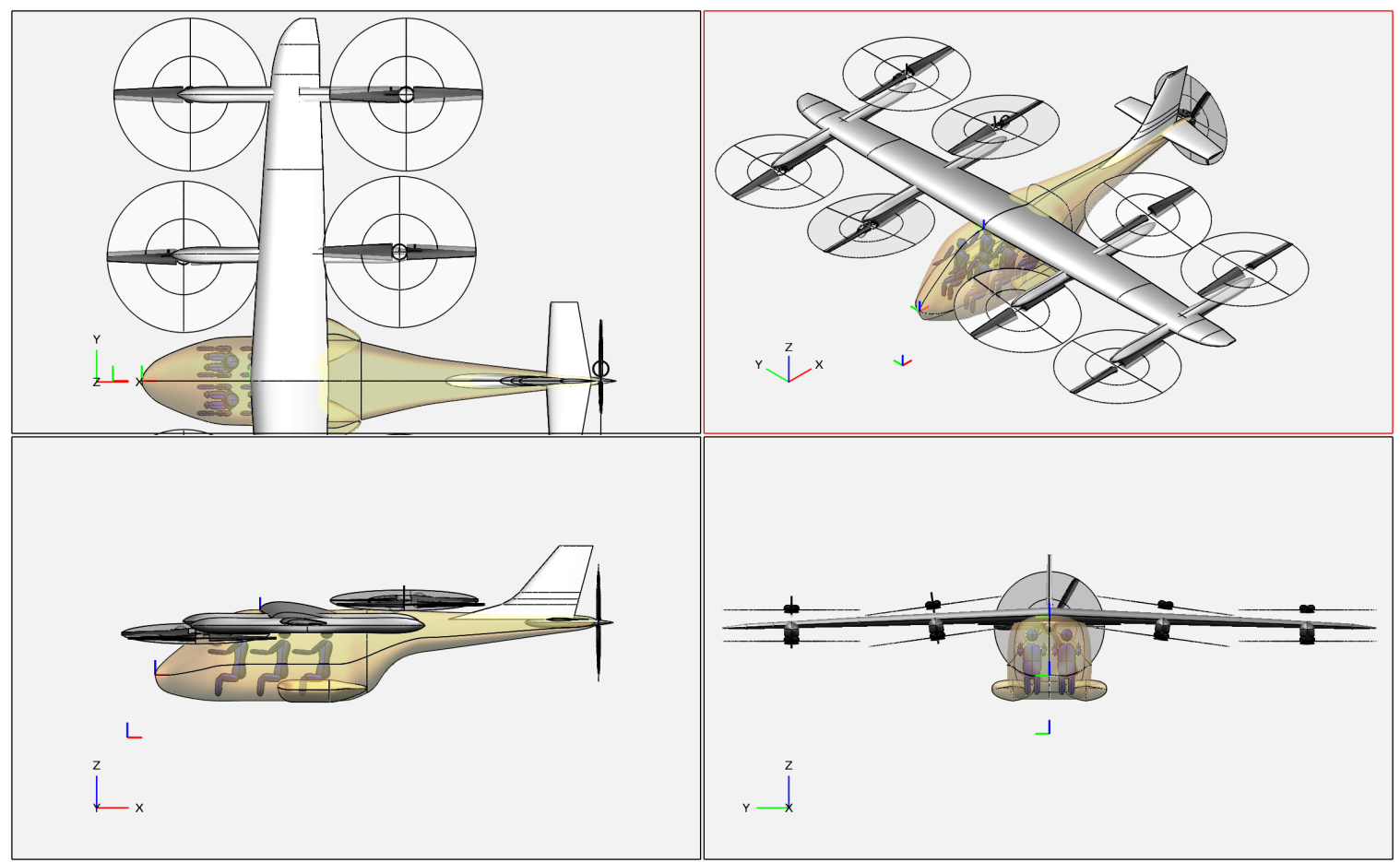

Fig. 6 Representation of Lift+Cruise VTOL Aircraft

the component which can be drawn from by motors as a tank. Additionally, this is a fairly rational approach, as transient demands can be met without continually chasing them with the turbine and generator.

Disk loading drives the lifting rotor design. Initial design for layout estimated a $5000 \mathrm{lb}$ DGW based on the other vehicles in this study, and assumed 8 psf disk loading. Growth of the vehicle caused the rotor size to grow, and lateral spacing grew accordingly.

There are several layout considerations which are accounted for in the design. The aircraft has a fuselage similar to that of the Side-by-Side, and a large wing span. The placement of the turboelectric unit in the fuselage necessitates a space in the aircraft for that installation. In the earlier tilt-wing concepts, we had a nacelle above the cabin, whereas the present Lift+Cruise has a buried installation; more detailed analyses will be required to assess the impact of each choice. A high mounted wing was selected for passenger clearance during ingress/egress. Lateral reposition of the aircraft will require the body roll axis moving to tilt the thrust vector, as in the Quadrotor, therefore a high wing provides more clearance for this maneuver near the ground. Canted inboard rotors keep the rotor plane from crossing passengers, which should limit the possibility of injury in the case of a catastrophic rotor failure. The forward rotors are mounted below the boom to reduce their adverse impact on the wing and aft rotors during transition. The lower placement of front rotors has an undesirable impact on passenger ingress/egress forward of the wing or to the sides, as the rotors are now close to head height. Boarding and deboarding the aircraft must include precautions to prevent passengers interacting with the rotors, so these features will be particular to the vertiport infrastructure and operational procedures.

A high L/De in cruise is desirable, since any savings in energy reduces overall size substantially, therefore a high aspect-ratio wing was selected. The placement of the fore and aft rotors on booms from the wing means that the minimum longitudinal spacing is dictated by wing chord. Pitch authority with the hover propellers is assumed to be a lesser concern, especially since the pusher can supply longitudinal force, so a high aspect ratio wing is believed to be acceptable.

There is a large uncertainty in the weights of the wing and lifting rotor supports, as these are quite different in the Lift+Cruise than in the existing aircraft from which the empirical equations were based. The wing was modeled using the standard NDARC fixed-wing parametric model (AFDD93), since the wing operates as a fixed-wing aircraft in forward flight and the lifting loads of the rotors are somewhat distributed. The mounting of rotor support booms to the wing has not been accounted for in the wing weight, and this likely means that the wing weight will be heavier than what has been estimated in this study. Unlike the side-by-side, jump takeoff should not be a large concern, as the rotors 


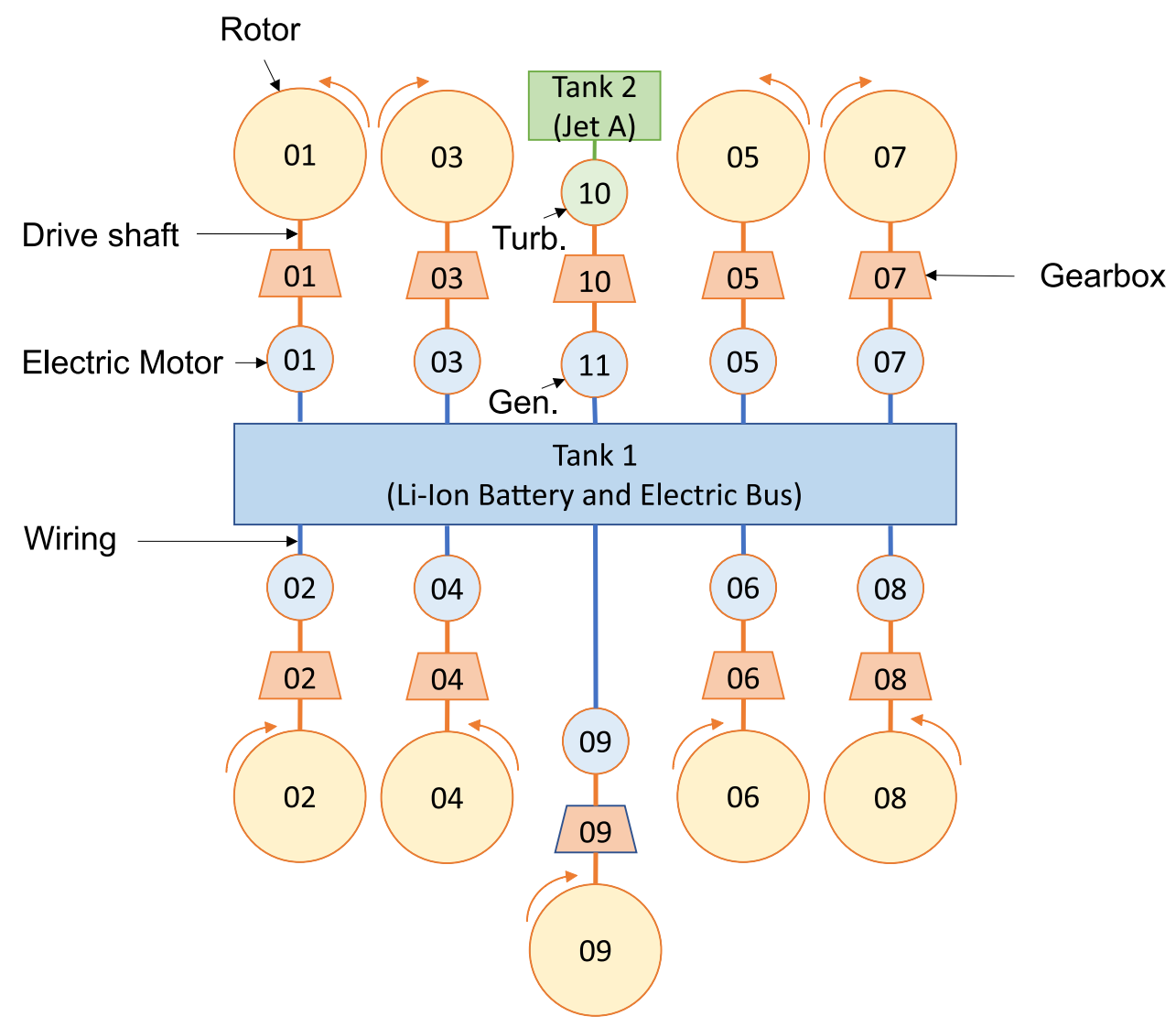

Fig. 7 Representation of Turboelectric Lift+Cruise Power Topology

cannot spin up and generate a lift increment as quickly as a collective actuation can, and the power limit of the drive system will likely limit maneuvering. Booms for mounting props need to handle thrust, torque, and a bit of moment in transition, as the hingeless fixed-pitch rotors will generate moments in response to edgewise operation. No special estimate of rotor-support boom weight was performed, with only the standard rotor support weights assumed-likely a quite optimistic assumption. Rotor weight may be reduced with a flapping rotor, which can use delta-3 as is common in tail rotors and the rotors on our reference Quadrotor, but for simplicity a fixed-pitch rotor was selected.

The electric components will require greater analysis in order to determine the required space and drag. A first cut at the sizing of wing internal space was performed, and a $22 \%$-thick wing was used as a starting point.

The control of a lift+cruise aircraft with RPM control in hover leads to a more complex design space than in traditional helicopters or fixed-wing aircraft. As previously mentioned, a high wing accommodates lateral maneuvering near ground. Yaw authority of RPM or collective variation is poor as rapid changes in speed get more difficult as size grows. To improve yaw authority, inboard rotors are canted outward to generate a side force which will increase yaw moment as thrust increases with rotor speed increases and reduce yaw moment as thrust decreases with slowing rotors. The cant angle on this high-rotor layout has two adverse impacts when rolling for lateral repositioning: an adverse side force opposite to the direction of intended displacement, and that same component of force is offset above CG reducing the net roll moment. Since the inboard rotors are nearer to the center of gravity in the butt-line direction, their rolling moment contribution for a force change is substantially less than for the outboard rotors. For these reasons, it makes sense to limit the change in thrust for the inboard rotors in response to rolling command, and use the outboard rotors as the major contributor to roll control. Adjacent rotors spin opposite each other for balanced layout, but other schemes may also be valid. Six or more rotors offer a simple solution for full redundancy in case of a single motor failure, in that pairs of rotors can be shut down while the remaining rotors are operated at higher thrust. With 6 rotors, the static thrust required from remaining operational rotors is $50 \%$ higher, with 8 rotors, it is $33 \%$ higher. It is also possible to employ a scheme with increased torque/rotor on a subset of operational rotors and decreased torque/rotor on a larger number operational rotors, due to indeterminate trim state. Different torque allocations are more easily implemented if 
Table 2 Lift+Cruise RPM-Controlled Lifters: Control State 1 (Helicopter Mode)

\begin{tabular}{|c|c|c|c|c|c|c|c|c|c|c|c|}
\hline $\begin{array}{l}\text { control number } \\
\text { IDENT_control } \\
\text { Positive command }\end{array}$ & $\begin{array}{c}1 \\
\text { coll } \\
+ \text { up } \\
\end{array}$ & $\begin{array}{c}2 \\
\text { latcyc } \\
\text { roll rt }\end{array}$ & $\begin{array}{c}3 \\
\text { lngcyc } \\
\text { nose dn }\end{array}$ & $\begin{array}{c}4 \\
\text { pedal } \\
\text { nose rt }\end{array}$ & $\begin{array}{c}5 \\
\text { flap } \\
\mathrm{dn}\end{array}$ & $\begin{array}{c}6 \\
\text { elevator } \\
\text { nose up }\end{array}$ & $\begin{array}{c}7 \\
\text { aileron } \\
\text { roll } \mathrm{rt} \\
\end{array}$ & $\begin{array}{c}8 \\
\text { rudder } \\
\text { nose } \mathrm{rt}\end{array}$ & $\begin{array}{c}9 \\
\text { pusher } \\
+ \text { coll } \\
\end{array}$ & $\begin{array}{c}10 \\
\text { hoverp } \\
+ \text { coll }\end{array}$ & $\begin{array}{c}11 \\
\text { gen amp } \\
+ \text { curr }\end{array}$ \\
\hline Rotor 1-8 T_Coll & 0 & 0 & 0 & 0 & 0 & 0 & 0 & 0 & 0 & 1 & 0 \\
\hline Rotor 9 T_Coll & 0 & 0 & 0 & 0 & 0 & 0 & 0 & 0 & 1 & 0 & 0 \\
\hline Rotor 1-9 T_lngcyc & 0 & 0 & 0 & 0 & 0 & 0 & 0 & 0 & 0 & 0 & 0 \\
\hline Rotor 1-9 T_latcyc & 0 & 0 & 0 & 0 & 0 & 0 & 0 & 0 & 0 & 0 & 0 \\
\hline Propulsion 1 T_DN & 100 & 100 & -100 & 50 & 0 & 0 & 0 & 0 & 0 & 0 & 0 \\
\hline Propulsion 2 T_DN & 100 & 100 & 100 & -50 & 0 & 0 & 0 & 0 & 0 & 0 & 0 \\
\hline Propulsion 3 T_DN & 100 & 50 & -100 & -50 & 0 & 0 & 0 & 0 & 0 & 0 & 0 \\
\hline Propulsion 4 T_DN & 100 & 50 & 100 & 50 & 0 & 0 & 0 & 0 & 0 & 0 & 0 \\
\hline Propulsion 5 T_DN & 100 & -50 & -100 & 50 & 0 & 0 & 0 & 0 & 0 & 0 & 0 \\
\hline Propulsion 6 T_DN & 100 & -50 & 100 & -50 & 0 & 0 & 0 & 0 & 0 & 0 & 0 \\
\hline Propulsion 7 T_DN & 100 & -100 & -100 & -50 & 0 & 0 & 0 & 0 & 0 & 0 & 0 \\
\hline Propulsion 8 T_DN & 100 & -100 & 100 & 50 & 0 & 0 & 0 & 0 & 0 & 0 & 0 \\
\hline Propulsion 9 T_DN & 0 & 0 & 0 & 0 & 0 & 0 & 0 & 0 & 0 & 0 & 0 \\
\hline Propulsion 10 T_DN & 0 & 0 & 0 & 0 & 0 & 0 & 0 & 0 & 0 & 0 & 0 \\
\hline Eng Grp 1-10 T_amp & 0 & 0 & 0 & 0 & 0 & 0 & 0 & 0 & 0 & 0 & 0 \\
\hline Eng Grp $11 \mathrm{~T} \_a m p$ & 0 & 0 & 0 & 0 & 0 & 0 & 0 & 0 & 0 & 0 & 1 \\
\hline
\end{tabular}

collective-pitch control is available, as thrust and torque are then separately controllable with RPM.

For NDARC trim purposes, which only considers quasi-steady operating states, the control connections in helicopter mode are shown in Table 2 For NDARC, IDENT_control is a descriptor of the logical control used for commanding some aspect of the aircraft behavior, and has legacy in the physical pilot controls. Therefore, "coll" or collective is the heave axis control in hover, but in forward flight "coll" is unused or connected to the pusher propeller thrust. Similarly, "latcyc" or lateral cyclic is roll and "Ingcyc" or longitudinal cyclic is pitch command. One special control for the turboelectric is "gen amp," which is usually trimmed to result in zero state of charge change in the battery, but may be controlled to zero for all-electic battery operation, as in the case of turboshaft engine failure.

\section{Technologies}

The concept aircraft descriptions include, importantly, assumptions about the kinds of technologies which will be present in the aircraft, and how these technologies scale. Some of the technology assumptions represent currently-fielded technologies, some represent advanced technologies which are at a low (less than 7) Technology Readiness Level, and some are aggressive targets which are required in order for the realization of UAM at a reasonable size and cost of the vehicles. For NASA, the expected performance and estimated space, weight and power allocations of each component in these concept vehicles is a target against which the value of developing a particular technology may be measured. Whenever possible, the same technologies were assumed for each concept aircraft. For components which are common with other conventional flight vehicles, the technologies are those expected for a high-technology composite aircraft.

\section{A. Battery technology}

The batteries for the concept vehicles are based on Lithium-Ion battery technology, with projections to advanced batteries with very high specific energy and specific power at the cell and pack level. The battery model has been described in Ref. [4] and installation overhead in Ref. [1]. The NDARC battery model has features to account for voltage reduction with current draw and depth of discharge. Battery-cell rated specific energy for this study is 650 $\mathrm{Wh} / \mathrm{kg}$, which is immediately reduced by $20 \%$ to $530 \mathrm{Wh} / \mathrm{kg}$ to account for: $5 \%$ of top-of-charge which is not utilized in order to preserve battery life, and 15\% bottom-of-charge which is a region of rapidly diminishing voltage. Further reduction in specific energy to account for $30 \%$ weight for battery management systems and pack structures yield an effective specific energy of $400 \mathrm{Wh} / \mathrm{kg}(1.31 \mathrm{MJ} / \mathrm{kg})$ at the pack level. 


\section{B. Motor and gearbox technology}

Electric motors come in many different types, and making weight comparisons is sometimes difficult because of the variation in the bookkeeping of various necessary elements for the motor system. For instance, some motors have clear distinctions between the mechanical system, the commutation and control system, and the cooling system, but many do not. For the present vehicles, we have assumed permanent magnet AC motors, which have a high torque-to-weight, with the following empirical relation included in NDARC:

$$
W_{\text {onemotor }}=0.3928 Q^{0.8587}
$$

With the large rotors, a lighter-weight solution is realizable with a higher-speed motor operating in conjunction with a speed-reducing gearbox, due to the lower weight scaling with torque for gearboxes than motors, as in the AFDD00 equation in NDARC, where $P_{D S L i m i t}$ is the gearbox torque limit, expressed as power at reference rotor speed, and $N_{\text {rotor }}$ is the number of main rotors attached to the gearbox:

$$
W_{\text {gearbox }}=95.7634 N_{\text {rotor }}^{0.38553} P_{\text {DSLimit }}^{0.78137} \Omega_{\text {motor }}^{0.09899} / \Omega_{\text {rotor }}^{0.80686}
$$

One caution when using a gearbox in an RPM-controlled rotor system is that the gearing creates a growth in the apparent inertia which the motor must accelerate proportional to the square of the gear reduction ratio. This greater apparent inertia can result in lower rotor response speed, which may cause the gearbox to be undesirable from a handling-qualities standpoint.

The motor weight needs to account for accessory components, such as inverters and speed controllers, heat exchangers, connectors, wiring, and shielding. In the present study, a fixed ratio of $63 \%$ weight for accessory weight to motor weight has been assumed, (i.e. motor tech factor of 1.63).

\section{Results}

For each of the three types of UAM vehicle, a battery-powered all-electric and turboshaft-powered aircraft were designed which met the same design mission criteria. A comparison of the attributes of these vehicles is shown in Table 3 For the Quadrotor and Side-by-Side aircraft, the design disk loading was varied to arrive at a lightweight, balanced design. For the Lift+Cruise aircraft, the initial intent was to aim for a lift rotor disk loading below 8 . A hard constraint on diameter of $10 \mathrm{ft}$ was imposed, since these are fixed-pitch hingeless rotors with RPM control, and the rotor inertia is expected to increase beyond the capability of RPM control to provide enough responsiveness for maneuvering at diameters over $10 \mathrm{ft}$. The actual limits on lift rotor size will be examined with future studies on handling qualities of the reference concept aircraft.

In all cases, the battery-powered vehicles were the heaviest and had the most installed power. The Side-by-Side concepts are lightest, followed by the Quadrotor, with the Lift+Cruise being heaviest. Installed power per lifter is fairly low in all cases, and within the domain of our calibration data (it should be noted that certified aviation motors are not in the database).

For very high values of cruise efficiency and very low values of hover efficiency and/or range, an aircraft can be sized that might have a very high hover current (high in terms of 1/hr C-rate, where today's technology is limited to about $2 \mathrm{C}$ discharge without excessive heating or cell damage), and this tends to be at odds with the technology for high specific energy. The basic relation which can be used to estimate hover C-rate ( $\left.x_{\text {hover }}\right)$ is shown in Equation 3 , and derived in Ref. [1].

$$
x_{\text {hover }}=\sqrt{W / 2 \rho A} \frac{\eta_{\text {cruise }}\left(L / D_{e}\right)}{\eta_{\text {hover }} F M} \frac{1}{\text { Range }}+\text { Constant }
$$

The equation indicates the sources of increased hover C-rate as disk loading (W/A), rotor losses (FM), cruise efficiency $\left(L / D_{e}\right)$, and range. The immediate implication is that if battery C-rate is a limitation, then the way to improve it (with a battery sized for the design mission) are to improve hover efficiency, and not expend effort improving cruise efficiency. In these concept vehicles, the highest hover current is $2.4 \mathrm{C}$, for the Battery powered Lift+Cruise aircraft. 2-3C is a reasonable current draw to expect from batteries in the near-term, so the hover power and battery size is probably reasonably matched.

\section{A. Quadrotor results and observations}

The vehicle optimum for gross weight and installed power comes at a low disk loading. As a result of the low disk loading, the best endurance speed is very low, but the best-range cruise speed is actually close to other vehicles. The 
Table 3 Comparison of Concept Vehicle Attributes

\begin{tabular}{|c|c|c|c|c|c|c|}
\hline Vehicle & Quad TS & Quad E & SbS TS & SbS E & $\mathrm{L}+\mathrm{C} \mathrm{TE}$ & $\mathrm{L}+\mathrm{C} \mathrm{E}$ \\
\hline Lifter Disk Loading $\left(\mathrm{lb} / \mathrm{ft}^{2}\right)$ & 3.5 & 3.0 & 5.0 & 3.5 & 9.6 & 13.1 \\
\hline Lifter Radius (ft) & 9.2 & 13.1 & 10.5 & 14.9 & 5.0 & 5.0 \\
\hline Solidity, thrust-weighted & 0.065 & 0.055 & 0.083 & 0.058 & 0.196 & 0.267 \\
\hline Hover tip Speed (ft/s) & 550 & 550 & 550 & 550 & 546 & 585 \\
\hline Autorotation Index & 0.95 & 1.69 & 0.95 & 1.64 & 0.47 & 1.23 \\
\hline Number Lift Engine/Motor & 1 & 4 & 2 & 2 & 8 & 8 \\
\hline MRP Power per lifter (hp) & 76 & 168 & 232 & 214 & 88 & 139 \\
\hline Number Cruise Engine/Motor & - & - & - & - & 1 & 1 \\
\hline Power per Cruiser (hp) & - & - & - & - & 446 & 628 \\
\hline Total Deliverable Power (hp) & 305 & 672 & 464 & 428 & 1152 & 1743 \\
\hline Total Installed Power (hp) & 305 & 672 & 464 & 428 & 3376 & 1743 \\
\hline Weight/Lift Power (lb/hp) & 12.8 & 14.0 & 10.7 & 12.6 & 7.8 & 7.4 \\
\hline Weight/Cruise Power (lb/hp) & 13.1 & 18.4 & 16.9 & 24.4 & 18.8 & 24.9 \\
\hline Cruise Drag D/q $\left(\mathrm{ft}^{2}\right)$ & 7.2 & 12.9 & 5.3 & 7.5 & 13.9 & 16.9 \\
\hline Fuselage & 1.4 & 1.4 & 1.6 & 1.6 & 1.7 & 1.7 \\
\hline Rotor Hubs & 4.8 & 9.7 & 1.0 & 2.1 & 0.9 & 1.2 \\
\hline$(\mathrm{D} / \mathrm{q}) /(\mathrm{W} / 1000)^{2 / 3}$ & 2.3 & 3.2 & 2.2 & 2.5 & 4.2 & 4.1 \\
\hline $\mathrm{C}_{D f}=(\mathrm{D} / \mathrm{Q}) / \mathrm{S}_{w e t}$ & 0.0059 & 0.0080 & 0.0082 & 0.0095 & 0.0141 & 0.0151 \\
\hline Battery Capacity (MJ) & - & 1331 & - & 846 & 160 & 1436 \\
\hline Battery Weight (lb) & - & 1567 & - & 997 & 188 & 1693 \\
\hline Fuel Tank Capacity (lb) & 179 & - & 147 & - & 176 & - \\
\hline DGW (lb) & 3735 & 6480 & 3468 & 4897 & 6013 & 8210 \\
\hline Empty Weight & 2345 & 5270 & 2111 & 3687 & 4627 & 7001 \\
\hline structure & 1101 & 1641 & 940 & 1235 & 2112 & 2575 \\
\hline rotor group & 325 & 628 & 196 & 345 & 748 & 948 \\
\hline Propulsion & 554 & 2671 & 522 & 1688 & 1530 & 3186 \\
\hline fuel system & 43 & 2038 & 38 & 1296 & 298 & 2201 \\
\hline drive system & 254 & 397 & 195 & 255 & 315 & 358 \\
\hline Systems & 502 & 536 & 501 & 507 & 522 & 540 \\
\hline flight controls & 91 & 108 & 93 & 93 & 134 & 152 \\
\hline $\mathrm{V}_{b e}$ at DGW 6kISA (KTAS) & 58 & 56 & 67 & 61 & 90 & 88 \\
\hline $\mathrm{V}_{b r}$ DGW 6kISA (KTAS) & 122 & 98 & 116 & 98 & 122 & 112 \\
\hline $\mathrm{V}_{\max }$ DGW 6kISA (KTAS) & 142 & 109 & 137 & 114 & 123 & 129 \\
\hline Design Mission 6kISA, Payload (lb) & 1200 & 1200 & 1200 & 1200 & 1200 & 1200 \\
\hline Energy burn (MJ) & 2667 & 1070 & 2206 & 686 & 2510 & 1113 \\
\hline Fuel burn (lb) & 137 & - & 114 & - & 129 & - \\
\hline $\mathrm{L} / \mathrm{D}_{e}=\mathrm{W}^{*} \mathrm{v} / \mathrm{P}$ & 4.9 & 5.8 & 5.9 & 7.2 & 7.2 & 8.5 \\
\hline Aircraft Hover FM & 0.69 & 0.70 & 0.69 & 0.68 & 0.70 & 0.74 \\
\hline Block time (min) & 42.9 & 51.7 & 46.4 & 54.5 & 46.5 & 49.1 \\
\hline Block speed (kt) & 105.0 & 87.1 & 97.0 & 82.6 & 96.7 & 91.7 \\
\hline Hover C-rate $(1 / \mathrm{hr})$ & - & 1.1 & - & 1.4 & 0.0 & 2.4 \\
\hline Cruise C-rate $(1 / \mathrm{hr})$ & - & 0.8 & - & 0.7 & 0.0 & 0.7 \\
\hline
\end{tabular}


climb segment sized the propulsion system, and as a result, the fallout top speed, $V_{\max }$, of the Turboshaft Quadrotor is the fastest of the concept vehicles sized for these requirements.

The Turboshaft Quadrotor is the second-lightest aircraft, and the fuel required for the design mission (fuel tank capacity) is nearly the same as that of the Turboelectric Lift+Cruise. The growth in weight due to battery propulsion is very pronounced, and the battery-powered Electric Quadrotor is 73\% heavier than the Turboshaft Quadrotor.

In terms of technology, the importance of high specific energy batteries is evident in these results. Rotor performance in hover and forward flight is predicted to be very good, and the overall vehicle efficiency for the quadrotors is very high in both modes. As before, a flapping rotor with appropriate delta-3 flap-pitch coupling, should allow this vehicle to fly efficiently in edgewise flight without lateral or longitudinal cyclic, and without incurring high root-bending stresses.

\section{B. Side-by-Side results and observations}

The Turboshaft Side-by-Side aircraft is the lightest weight solution among those examined here. At a disk loading of $5.0 \mathrm{psf}$, the Turboshaft Side-by-Side is a bit less efficient in hover and cruise than the Electric Side-by-Side, but the shorter cross-bar and slightly larger engines make for a lighter vehicle overall.

The Electric Side-by-Side is the lightest of the battery-powered concepts, and at $41 \%$ heavier than its turboshaft analog, is in between the growth factor for the other two concepts (Electric Lift+Cruise is 37\% heavier for battery compared to turboelectric).

If all-electric aircraft are going to be pursued for the UAM mission, then the attributes of the side-by-side or perhaps the quadrotor are likely to make the most sense: good hover efficiency, reasonable cruise efficiency, and a vehicle empty weight fraction which does not pay too much for the cruise efficiency. The Electric Quadrotor is $11 \%$ better in terms of hover $\mathrm{lb} / \mathrm{hp}$, but is $25 \%$ lower in terms of cruise $\mathrm{lb} / \mathrm{hp}$. Despite the slight advantage for the Electric Quadrotor in terms of structural weight/empty weight ( $31 \%$ vs $33.5 \%$ ), the rapid growth of battery weight makes the Electric Side-by-Side $24 \%$ lighter for the design mission with $36 \%$ less installed power.

\section{Lift+Cruise results and observations}

For this study, the turboelectric battery sizing was set by at least 2 minutes of hover or no more than $14 \mathrm{C}$ discharge rate (i.e., discharge rated capacity of battery in $1 / 14$ of an hour, 4.3 minutes, or more), which is the assumed maximum burst discharge rate. At this discharge rate, the batteries will likely no longer be usable, but this time should be sufficient for the aircraft to perform a safe, emergency landing. The discharge rate is the active sizing constraint for the battery.

The climb segment at $900 \mathrm{ft} / \mathrm{min}$ is the sizing condition for the pusher motor (Motor 9) and its gearbox (Propulsion Group 9).

Rotor power for aircraft with rotors operating in the wake of upstream rotors is a cause for concern. Based on the results of analysis of the quadrotor, the rear rotor was moved upward relative to the forward rotor to reduce power required in forward flight. One extra factor driving transition power is the presence of the wing. As the wing operates in the wake of the front rotors its angle of attack will be lower, and generate less lift in transition. Another difficulty is that without cyclic control, the only way to generate forward thrust with the lifting rotors is to tilt the rotors forward, which is only possible by tilting the entire aircraft forward, also lowering the angle of attack of the wing. In the extreme, the wing may be generating net downward lift, which needs to be countered by all of the rotors. The rear rotors need to generate a higher thrust in any event, in order to maintain the forward pitch of the aircraft. As a result, operating the pusher for X-force is a desirable trade, despite the relative inefficiency in low-speed flight (large rotors moving a lot of air and a force equal to the weight of the aircraft would only need a small forward component to generate a lot of forward thrust with little loss of vertical thrust. Because of all of the interactions and various limits which may be reached, forceand moment-trimmed flight must be analyzed through conversion, rather than a simple energy and force method.

A control mode with prescribed body pitch through transition was used for conversion from hover to cruise. The body pitch required for initially flying on the wing is relatively high (flying near wing stall), whereas the best pitch for conversion or cruise is low. Therefore, transitioning from lifters operating to flying on the wing will require a more detailed analysis and probably a time-domain simulation. A plot of some aspects of hover-to-cruise conversion is shown in Fig. 8 One important observation is that with fixed-pitch lift rotors, the thrust is relatively constant, but the power and speed required to achieve that thrust reduces substantially as edgewise speed increases. The blade loading, $C_{T} / \sigma$, of the rotors therefore increases, and can approach stall. Solutions to this are to reduce the hover blade loading with greater rotor speed and/or to increase the blade chord.

Noise is an important consideration for UAM, since there will be many vehicles operating in close proximity to large populations for many hours of the day. While no noise analysis has yet been performed on these specific concept vehicles 


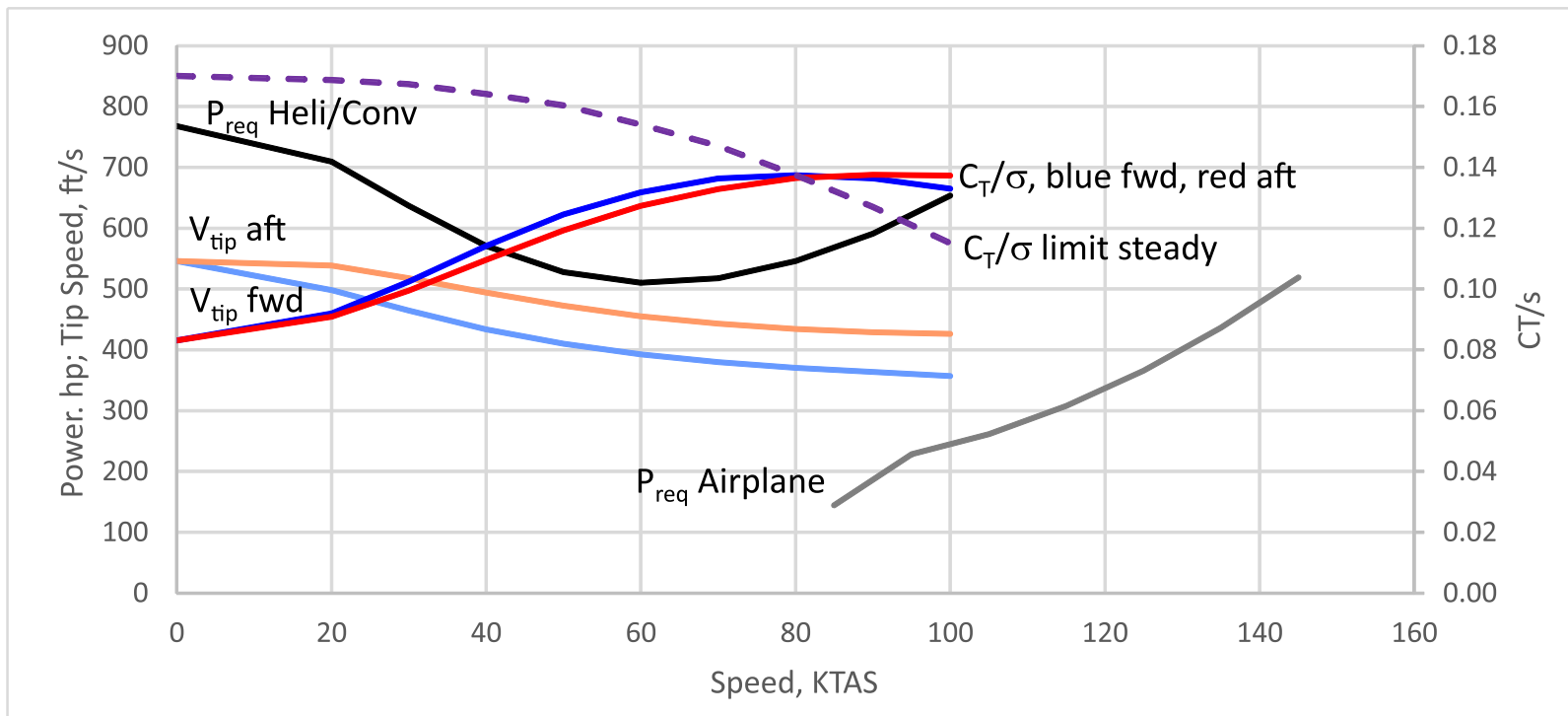

Fig. 8 Variation of selected parameters for Turboelectric RPM-Controlled Lift+Cruise in slow-speed flight

to date, future work will include noise and annoyance analysis. As a rule of thumb, tip speed of the rotors was kept low by traditional rotorcraft standards, at around 550-600 ft/s in hover for the design mission, in order to reduce noise. Rotor blade-to-blade and rotor-to-rotor interference can be the source of significant noise due to blade vortex interaction (BVI), and the placement of the rotors was selected to eliminate or reduce the likelihood of these interactions, except in the case of the side-by-side, where the wake of one rotor will necessarily interact with the wake of the other rotor.

The safety approach in the Lift+Cruise concepts is to mitigate the loss of any single rotor with redundancy, and in the case of the Turboelectric, to mitigate fuel starvation with a battery. No autorotation is possible without collective, so a gliding landing or another recovery system should be considered for the cases of propulsive power loss. Without electrical power, we cannot even consider control of RPM, so the electric power system should have some redundancy to account for control requirements in the event of primary power loss.

The weight of the Lift+Cruise concepts is heavier in general than for the other vehicles. This is not driven by the cruise power draw, as the $L / D_{e}$ of the Lift+Cruise is indeed higher than the other vehicles. Hover power is higher, but the most likely targets for reducing vehicle weight are the extra empty weight items on board in hover (wing and propeller). The wing weight does not appear to be unusually heavy, and excursions on aspect ratio indicated that lower aspect ratios would only result in heavier aircraft.

Lift rotor performance is predicted to be quite good, as the vehicle figure of merit is actually highest for the Lift+Cruise configurations due to the very small download and rotors which may be optimized for hover and low-speed edgewise flight. Lowering disk loading could improve the hover performance, but the rotor diameter is at the constraint. Adding more rotors may allow improvement in this regard, and will be studied. 


\section{Areas for Research}

\section{A. Tools}

Many of the critical uncertainties in our estimates involve component weights. The exceptionally rapid growth of battery weight with vehicle weight for a given mission means that small changes in weight will cascade quickly into a much larger aircraft. The acceptable structural weight of a UAM vehicle needs to account for not only flight loads but also crash events. Our weight methodology thus far has relied on crashworthy rotorcraft in the database, and the fuselages and landing gear selected for the concept vehicles do not appear to be wildly different from existing rotorcraft.

For the Lift+Cruise vehicles, a new structures methodology for conceptual design is needed for booms due to their different loading and dynamics. The boom or low-lift-capability wing element is just one of the features which is present in each of the three types of aircraft examined in the present study, and it is unclear which modeling approach is appropriate for these, or even if a single approach is valid across the types.

An approach being pursued is similar to that described in Ref. [11], which uses OpenVSP geometry as the starting point for a finite element mesh discretization and structural sizing for prescribed load cases. With such a tool, advances in materials and structural concepts may be accurately predicted earlier in the design process, enabling higher-confidence decisions in which vehicle types to pursue.

Our present methods for modeling the weight of accessories to motors and batteries and wiring are likely inadequate. While we hope that the consistent overhead weight fractions used across the concepts removes systematic bias against a particular type, we cannot assure that a particular type has not been allowed to take advantage of unique features. One other glaring area of modeling deficiency in electric components is the quasi-steady approach taken to modeling conditions and missions, which does not capture some sizing which is driven by transient heating. Ref. [12] presents some interesting analysis which indicates that transient modeling may be necessary to size components in an electrical system for VTOL operations.

The integration of handling qualities considerations in the design process has been a subject of research, and these concept vehicles have not yet been designed with integrated handling qualities analysis. For each aircraft, there is a question as to whether or not the performance-sized vehicles have adequate control authority, bandwidth, phase margins, and stability.

\section{B. Datasets}

At the present time, there are no manned electric VTOL vehicles which have been certified for operation or undergone extensive testing with publicly-available data. The lack of component and integrated system tests mean that tools for analyzing and designing these aircraft do not have a source for validation. In addition to the known flaws in the models, the lack of a known set of certification requirements means that we have to make many assumptions about the safety features and operations which will be required.

Two small-scale wind tunnel test rigs are being developed by NASA to study interactional aerodynamics of vehicles with multiple rotors: a side-by-side test rig and a multirotor test rig. While these test rigs will have scale effects to deal with and will not address dynamics, it is important that at least one part of the problem, aerodynamic interaction, is being evaluated.

\section{Propulsion Technologies}

Generally, airworthy electric components are areas for research; we have made assumptions about the motors, controllers, wiring, generators, and battery packs. The biggest unknown is the performance of batteries in VTOL aircraft applications. The present X-57 development at NASA should help us with not only airworthy battery data, but also with questions of power distribution and allocation in a distributed electric system.

\section{Edgewise fixed-pitch rotors}

The quadrotor and lift+cruise aircraft, when operating with RPM control, have a high blade loading in transition, and blade stall may be an issue. The solutions of adding more blade area and increasing hover tip speed may have negative consequences for acoustics. Another solution may be to use high-lift airfoils, as the fixed-pitch rotor does not have pitch link loads to worry about. The question of when RPM control can generate appropriate handling qualities is a question which must be answered. 


\section{Summary}

Three types of VTOL aircraft were designed for Urban air Mobility missions. These vehicles represent a set of technologies and design approaches for turboshaft- and battery-powered aircraft. The vehicle models and descriptions

will be available for further refinement and analysis by researchers. A lift+cruise aircraft has been designed and initial sizing and performance analysis has been performed.

\section{Acknowledgements}

This work is funded by NASA's Aeronautics Research Mission Directorate through the Revolutionary Vertical Lift Technology Project of the Advanced Air Vehicle Program.

\section{References}

[1] Johnson, W., Silva, C., and Solis, E., “Concept Vehicles for VTOL Air Taxi Operations," AHS Specialists' Conference on Aeromechanics Design for Transformative Vertical Flight, San Francisco, CA, 2018.

[2] Patterson, M. D., Antcliff, K. R., and Kohlman, L. W., "An Exploration of Urban Air Mobility Mission Requirements,” AHS International 74th Annual Forum and Technology Display, Phoenix, AZ, 2018.

[3] Silva, C., Johnson, W., and Solis, E., "Multidisciplinary Conceptual Design for Reduced-Emission Rotorcraft," AHS Specialists' Conference on Aeromechanics Design for Transformative Vertical Flight, San Francisco, CA, 2018.

[4] Johnson, W. R., "NDARC NASA Design and Analysis of Rotorcraft," NASA/TP-2015-218751, NASA, Moffett Field, CA, 2015.

[5] Hahn, A., "Vehicle Sketch Pad: Parametric Geometry for Conceptual Aircraft Design," AIAA 2010-657, AIAA, 2010.

[6] Johnson, W. R., “CAMRAD II References," retrieved from http://johnson-aeronautics.com/documents/CAMRADreferences.pdf, Palo Alto, CA, 2017.

[7] Moore, K. T., Naylor, B. A., and Gray, J. S., "The development of an open-source framework for multidisciplinary analysis and optimization," 10th aiaa/issmo multidisciplinary analysis and optimization conference, Victoria, Canada, 2008.

[8] Meyn, L. L., "Rotorcraft Optimization Tools: Incorporating Design Codes into Multi-Disciplinary Design, Analysis and Optimization," AHS Specialists' Meeting on Aeromechanics Design for Transformative Vertical Lift, San Francisco, CA, 2018.

[9] Hirschberg, M., "Meet Cora: Kitty Hawk Unveils 2-Seat eVTOL," Vertiflite, 3, Vol. 64, AHS International, Fairfax, VA, 2018, pp. 44-46.

[10] Swartz, K. I., “Charging Forward: New eVTOL Concepts Advance,” Vertiflite, 4, Vol. 63, AHS International, Fairfax, VA, 2017, pp. 24-29.

[11] Winter, T., "M4 Structures Studio for OpenVSP,” OpenVSP Workshop 2017, OpenVSP.org, Pismo Beach, CA, 2017.

[12] Danis, R. A., Green, M. W., Freeman, J. L., and Hall, D. W., "Examining the Conceptual Design Process for Future Hybrid-Electric Rotorcraft," NASA/CR-2018-219897, NASA, Moffett Field, CA, 2018. 